\title{
Modified axial lead system in children
}

Sir,

I commend Dr MacFarlane and his colleagues for their efforts to modify McFee and Parungao's axial lead system so as to simplify electrode placement in children (MacFarlane et al., 1977, British Heart fournal, 39, 1102).

However, I should like to sound a note of caution. Using internipple distance rather than height might introduce a systematic error in evaluating children with widely spaced nipples (shield chest). This may be of practical significance, since Turner's syndrome, Noonan's syndrome, and the fetal hydantoin syndrome are each associated with congenital heart disease and widely spaced nipples (Smith, 1976).

\author{
W. R. Pearl, \\ William Beaumont Army Medical Center, \\ El Paso, Texas, USA.
}

\section{Reference}

Smith, D. W. (1976). Recognizable Patterns of Human Malformation, pp. 46, 50, and 346. W. B. Saunders, Philadelphia.
This letter was shown to Drs Macfarlane and Coleman who reply as follows:

Sir,

Dr Pearl is correct in sounding a note of caution on the use of internipple distance rather than height when placing the axial lead system electrodes in children with widely spaced nipples (shield chest). The simplest solution to this problem is to use the original method of McFee and Parungao (1961), namely spacing the chest electrodes in proportion to the child's height. We feel however that in children with any type of chest deformity, chest electrode placements with any lead system will be subject to error.

Peter W. Macfarlane, Eric N. Coleman, Royal Infirmary, and Royal Hospital for Sick Children, Glasgow.

Reference

McFee, R., and Parungao, A. (1961). An orthogonal lead system for clinical electrocardiography. American Heart fournal, 62, 93-100.

\section{Notices}

\section{Fourth Annual Pediatric and Adolescent Echocardiography Course}

This course will be held on 10 to 12 November 1978 in Las Vegas, Nevada. Sponsored by the American Society of Echocardiography, American Institute of Ultrasound in Medicine and H.E.L.P. Inquiries should be sent to: Pediatric Echocardiography Course, 4340 Placita Panuco, Tucson, Az. 85718, USA 602/882-6508.

\section{Third Symposium on Echocardiology}

The third Symposium on Echocardiology will be held at the Erasmus University, Rotterdam, the Netherlands on 20, 21, and 22 June 1979. A commercial and scientific exhibition will be held at the same time.

Deadline for abstracts 1 November 1978.

For further details, write to: 3rd Symposium on Echocardiology, Thoraxcenter EE 2302 A, P.O. Box 1738, 300 Dr Rotterdam, The Netherlands. Attn. Mr C. T. Lancée. 